\title{
Lagos bat virus virulence in mice inoculated by the peripheral route
}

\author{
W. MARKOTTER ${ }^{1 *}$, I. V. KUZMIN ${ }^{2}$, C. E. RUPPRECHT ${ }^{2}$ AND L. H. NEL ${ }^{1}$ \\ ${ }^{1}$ Department of Microbiology and Plant Pathology, Faculty of Natural and Agricultural Sciences, University of \\ Pretoria, South Africa \\ ${ }^{2}$ Poxvirus and Rabies Branch, National Center for Zoonotic, Vector-borne and Enteric Diseases, Centers for \\ Disease Control and Prevention, Atlanta, GA, USA
}

(Accepted 9 December 2008; first published online 15 January 2009)

\section{SUMMARY}

Lagos bat virus (LBV) constitutes genotype (gt) 2 in the Lyssavirus genus. In contrast to the gt 1 lyssavirus, rabies virus (RABV), LBV was reported to have markedly reduced levels of peripheral pathogenicity. However, this opinion was based on a study of one isolate of LBV only and the reduction in pathogenicity was essentially attributed to the amino-acid substitution at position 333 of glycoprotein ectodomain. In the present study we have demonstrated that peripheral pathogenicity of representatives of LBV in a murine model is as high as that of RABV. Comparison of amino-acid substitutions among the viral glycoproteins, demonstrated significant differences within two antigenic sites between different phylogenetic lineages of LBV. Such molecular variability potentially contributes to differences in peripheral pathogenicity of lyssaviruses.

Key words: Africa, glycoprotein, Lagos bat virus, lyssavirus, pathogenicity, rabies.

\section{INTRODUCTION}

Lagos bat virus (LBV) constitutes genotype (gt) 2 in the Lyssavirus genus, family Rhabdoviridae [1]. With the development of molecular biology techniques, the Lyssavirus genus was divided into seven genotypes based on genetic distances. Rabies virus (RABV, gt1) circulates worldwide, whereas LBV, Mokola virus (MOKV, gt3) and Duvenhage virus (DUVV, gt4) have only been isolated from the African continent. European bat lyssaviruses 1 (EBLV-1, gt5) and 2 (EBLV-2, gt6) are present in Europe, and Australian

\footnotetext{
* Author for correspondence: Dr W. Markotter, Department of Microbiology and Plant Pathology, Faculty of Natural and Agricultural Sciences, University of Pretoria, Pretoria, 0001, South Africa.

(Email: wanda.markotter@up.ac.za)
}

bat lyssavirus (ABLV, gt7) has been identified from the Australian continent. All lyssavirus genotypes have been reported to be pathogenic for animals, and with the exception of gt2, were also reported to cause encephalitis in humans. Four new lyssaviruses, currently listed as tentative species in the Lyssavirus genus, were isolated from bats in Eurasia, i.e. Irkut (IRKV) [2], Aravan (ARAV) [3, 4], Khujand (KHUV) [4] and West Caucasian bat virus (WCBV) [2]. Based on phylogeny, serological cross-reactivity and peripheral pathogenicity to mice, lyssaviruses were divided into two phylogroups [5]. Phylogroup I comprised of genotypes 1, 4, 5, 6, 7 (as well as IRKV, ARAV and KHUV). Phylogroup II includes LBV and MOKV. Members of phylogroup I have been shown to be pathogenic for mice when inoculated via the intracerebral (i.c.) and intramuscular (i.m.) routes. 
Table 1. Information about lyssavirus isolates used in experimental infections of mice

\begin{tabular}{|c|c|c|c|c|c|}
\hline Virus name & Genotype & $\begin{array}{l}\text { Year of } \\
\text { isolation }\end{array}$ & Geographical origin & Animal species & Reference \\
\hline WAmyotis & 1 & 2004 & Washington, USA & Bat (Myotis sp.) & $\begin{array}{l}\text { Present } \\
\text { study }\end{array}$ \\
\hline $\operatorname{MOKVSA}(252 / 97)$ & 3 & 1997 & South Africa & Cat & {$[31]$} \\
\hline LBVCAR1974 & 2 (Lineage C) & 1974 & Central African Republic & Bat (Micropteropus pusillus) & [32] \\
\hline LBVSA1982 & 2 (Lineage $\mathrm{C}$ ) & 1982 & South Africa & Cat & [33] \\
\hline LBVSEN1985 & 2 (Lineage A) & 1985 & Senegal & Bat (Eidolon helvum) & [34] \\
\hline LBVZIM1986 & 2 (Lineage C) & 1986 & Zimbabwe & Cat & {$[35]$} \\
\hline LBVAFR1999 & 2 (Lineage A) & 1999 & $\begin{array}{l}\text { Imported into France from an } \\
\text { unknown origin in Africa }\end{array}$ & Bat (Rousettus aegyptiacus) & [36] \\
\hline LagSA2003 & 2 (Lineage $\mathrm{C}$ ) & 2003 & South Africa & Bat (Epomophorus wahlbergi) & [37] \\
\hline LagSA2004 & 2 (Lineage C) & 2004 & South Africa & Bat (Epomophorus wahlbergi) & [37] \\
\hline Mongoose2004 & 2 (Lineage C) & 2004 & South Africa & Mongoose (Atilax paludinosus) & [38] \\
\hline LBVSA2006 & 2 (Lineage C) & 2006 & South Africa & Bat (Epomophorus wahlbergi) & [39] \\
\hline
\end{tabular}

Members of phylogroup II were shown to be pathogenic for mice only when inoculated via the i.c. route but not when inoculated i.m. Importantly, however, this result was based on a study of a single isolate of LBV and a single isolate of MOKV [5]. Members of phylogroup I cross-neutralize each other. The same is true for phylogroup II, but very limited crossneutralization was shown between phylogroups I and II [5]. It has been suggested that WCBV could be considered as a representative of an independent phylogroup III in lieu of genetic distance and absence of serological cross-reactivity with both phylogroups I and II members [6, 7]. Preliminary pathogenicity studies indicated that WCBV was pathogenic for mice when inoculated i.c. but not i.m., as was observed for phylogroup II, but this virus was pathogenic for hamsters and bats when inoculated i.m. [7]. Commercial rabies vaccine strains all belong to gt1 and there is no evidence of their lack of efficacy against any gt 1 viruses although they are much less efficacious against the rabies-related lyssaviruses (gt2-gt7) [8]. For example, various rabies vaccines and anti-rabies immune globulins have been shown to fail to protect animals against MOKV, LBV and WCBV $[6,9,10]$.

The lyssavirus genome codes for five proteins: Nucleoprotein (N), Phosphoprotein (P), Matrixprotein $(\mathrm{M})$, Glycoprotein $(\mathrm{G})$ and the RNA polymerase (L). $G$ is the most important protein for interaction of virions with host cell receptors and for development of humoral immunity [11-16]. In addition, the $\mathrm{Arg} / \mathrm{Lys}^{333}$ amino acid (positively charged amino acid) in the $\mathrm{G}$ protein ectodomain was identified as being essential for the peripheral virulence of RABV $[14,16]$. Previous genetic analysis indicated that the $\mathrm{Arg} / \mathrm{Lys}^{333}$ is replaced by an $\mathrm{Asp}^{333}$ in phylogroup II lyssaviruses, probably resulting in their reduced pathogenicity [5]. Amino-acid (aa) substitutions in antigenic site II (aa $34-42$ and aa 198-200) of G protein in RABV result in a reduction of pathogenicity in adult mice when inoculated via the i.m. route [17].

When complete N, P, M and G genes of $13 \mathrm{LBV}$ isolates were analysed phylogenetically, the results identified three different lineages (A-C) of LBV [18]. One of these lineages (lineage A), demonstrated significant sequence diversity, and was suggested as a new lyssavirus genotype [18]. The present study was designed to compare the pathogenicity of several isolates of LBV that represent two of the previously three identified phylogenetic lineages of this virus [18], with representatives of RABV and MOKV. The experiments were performed in a murine model, comparing different doses of the viruses and routes of inoculation. Amino-acid substitutions along $G$ protein, previously suggested to be important for peripheral pathogenicity of lyssaviruses, were also compared.

\section{METHODS}

Eleven lyssavirus representatives were included in the present study (Table 1). These isolates were amplified in suckling mouse brain using i.c. inoculation. Selection of the LBV representatives was based on their phylogenetic positions in lineages $\mathrm{A}$ and $\mathrm{C}$ (Fig. 1) and their ability to be amplified to significant titres by mouse inoculation. The single available 


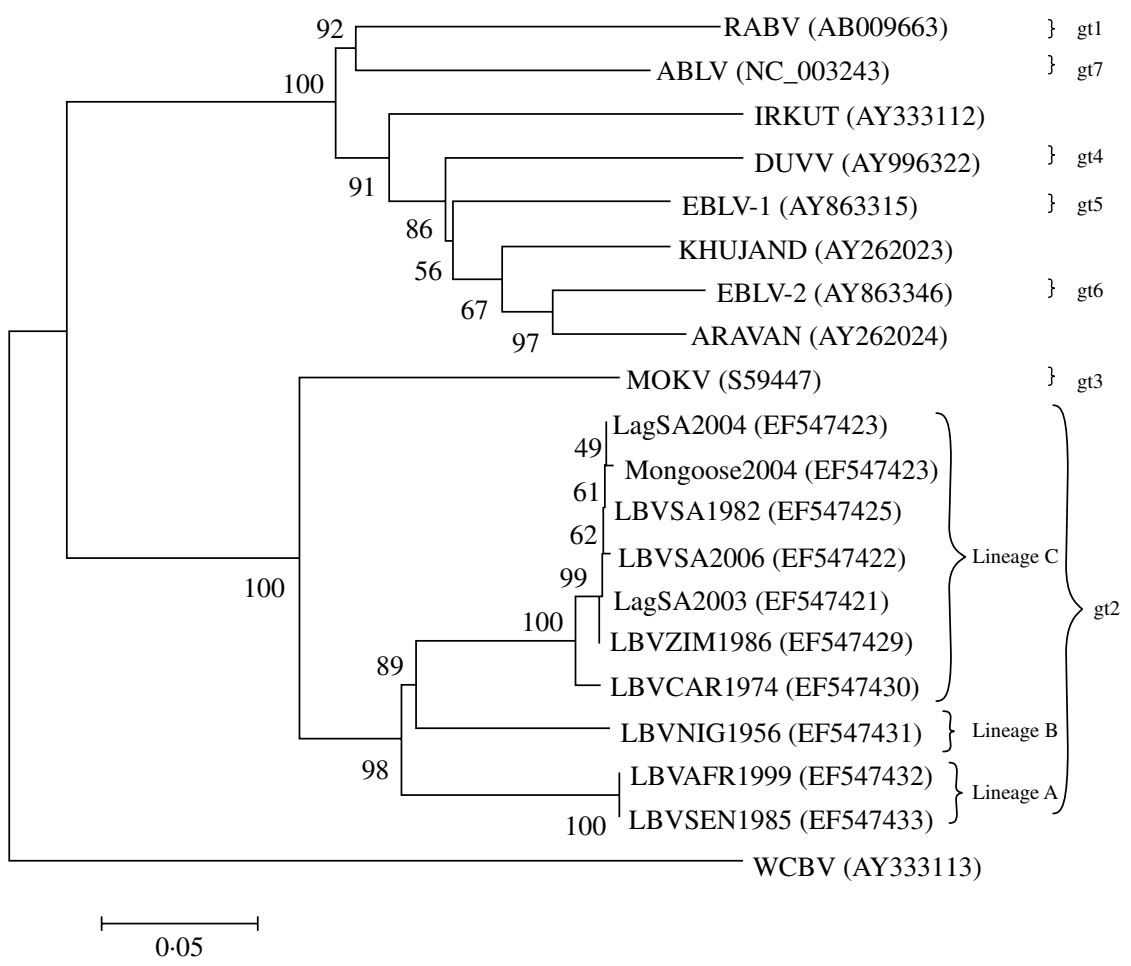

Fig. 1. Neighbour-joining (NJ) phylogenetic tree based upon the 439 amino acids of the ectodomain of the G protein of representatives of the lyssavirus genus, obtained by the NJ method. GenBank accession numbers are indicated for each isolate. Bootstrap values are indicated at the nodes and branch lengths are drawn to scale.

isolate of lineage B (LBVNIG1956) was not included because titres of this virus were low even after extensive passaging in mouse brain and cell cultures. The presence of lyssavirus antigen in the mouse brains was confirmed by direct fluorescent antibody test (FAT) using FITC-labelled monoclonal anti-rabies globulin (Jujirebio Diagnostics, USA) [19]. Ten percent mouse brain suspensions were prepared in Minimum Essential Medium (MEM-10, Gibco, USA) supplemented with $10 \%$ fetal calf serum. The suspensions were centrifuged at $3200 \mathrm{~g}$ for $15 \mathrm{~min}$ and stored at $-80{ }^{\circ} \mathrm{C}$. The titre of the inoculum was determined by i.c. inoculation of virus dilutions into 4-week-old outbred ICR mice, and the $50 \%$ mouse i.c. lethal dose $\left(M_{I C L D}\right)$ was calculated using the SpearmanKarber method [20].

Four-week-old ICR mice (obtained from Harlan Sprague-Dawley, USA) were used for experimental infections. Each mouse was identified with an ear tag providing a unique number (National Band and Tag Co., USA). All animal care and experimental procedures were performed in compliance with the Centers for Disease Control and Prevention Institutional Animal Care and Use Guidelines (USA). The mice were inoculated with lyssavirus isolates using different routes of inoculation and different doses of inoculum: group A $\left(10^{2} \mathrm{MICLD}_{50}\right.$ i.c. $)$, group B $\left(10^{3}\right.$ MICLD $_{50}$ i.m.), group C (106 MICLD $_{50}$ i.m.). Each group consisted of five mice. Mice were observed for 56 days and clinical signs and mortality were recorded daily. The i.m. inoculation was performed into the gastrocnemius muscle, in a total volume of $50 \mu$ l. The i.c. inoculation was performed in a total volume of $30 \mu 1$ as described previously [21]. The FAT was performed on mouse brain collected from succumbed or euthanized mice at the end of the experiment on day 56 . The nucleotide sequences of the complete $\mathrm{G}$ genes of LBV isolates were generated as described previously [18]. Nucleotide sequences obtained were assembled and edited using Vector NTI 9.1.0 (Invitrogen, USA) and amino-acid sequences were deduced using the translate function of this program. Multiple sequence alignments were generated using the Clustal X program [22].

\section{RESULTS}

\section{Susceptibility}

The i.c. inoculation of mice with gt1-gt3 lyssavirus isolates produced similar pathogenicity profiles, all leading to $100 \%$ mortality (Fig. 2). Intramuscular 


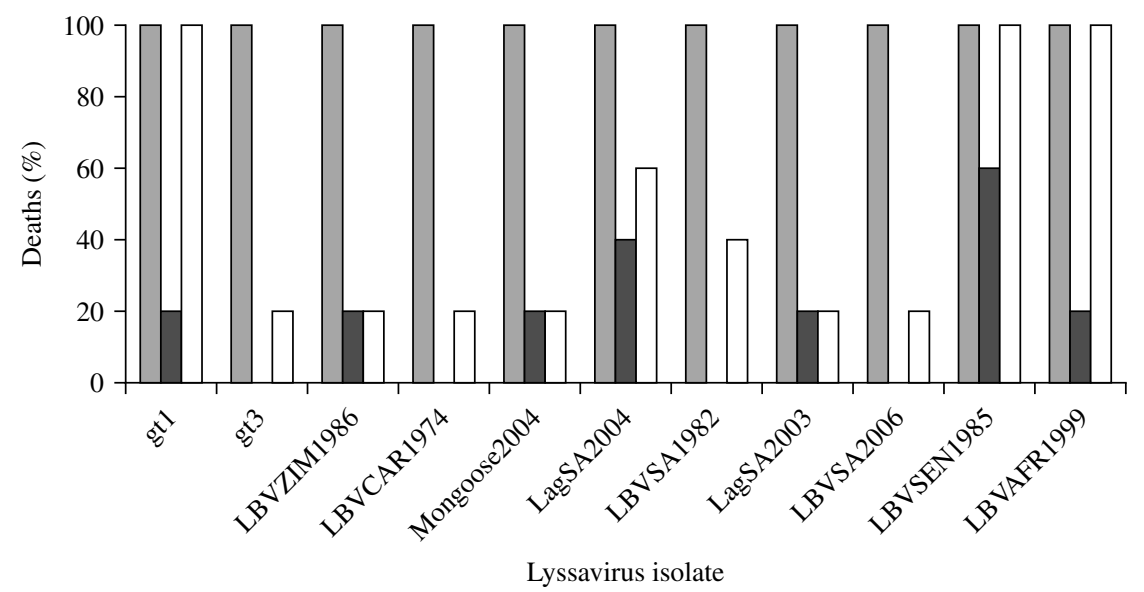

Fig. 2. Virulence of genotype (gt) 1 (WAmyotis), gt2 and gt3 [MOKVSA(252/97)] lyssaviruses in 4-week-old mice after intracerebral (i.c.) and intramuscular (i.m.) inoculation. Results are expressed as a percentage of rabid animals after observation for 56 days. Different viral doses were introduced: (a) $\square, 10^{2}$ MICLD $_{50}$ i.c.; $(b) \square, 10^{3} \operatorname{MICLD}_{50}$ i.m.; $(c) \square, 10^{6}$ MICLD $_{50}$ i.m.

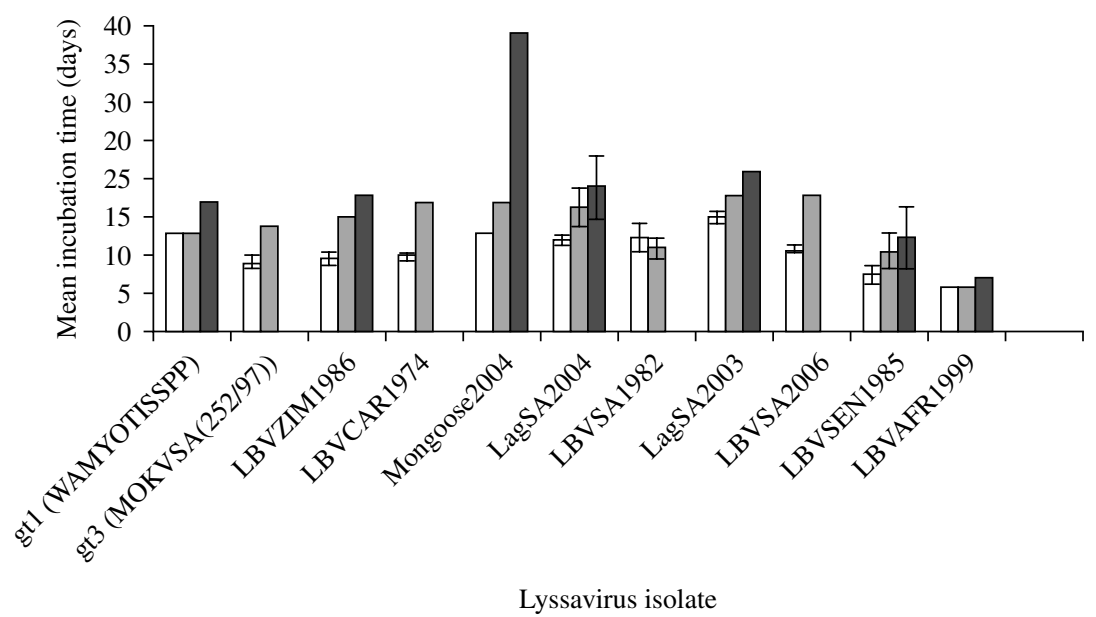

Fig. 3. Mean incubation time (days) of lyssavirus isolates after different routes of inoculation [intracerebral (i.c.) and intramuscular (i.m.)] and different viral doses were introduced into 4-week-old mice. The standard deviation (s.D.) is indicated. Some s.D. values were 0. (a) $\square, 10^{2} \operatorname{MICLD}_{50}$ i.c.; (b) $\square, 10^{6} \operatorname{MICLD}_{50}$ i.m.; (c) $\square, 10^{3} \operatorname{MICLD}_{50}$ i.m.

inoculation with gt 1-gt3 lyssaviruses produced more variable results. When a high dose $\left(10^{6} \mathrm{MICLD}_{50}\right)$ was used, all viruses were able to induce disease and subsequent death, but they were not equally virulent. At this dose, the RABV (isolate WAmyotis) and two of the LBV isolates, both from lineage A (LBVSEN1985 and LBVAFR1999), caused 100\% fatality rates after i.m. administration of the inoculum. Other LBV isolates injected i.m. at this dose caused rabies in $20-60 \%$ of mice. When a representative of gt3 [isolate MOKVSA(252/97)] was inoculated i.m. at this dose, only $20 \%$ of the mice succumbed. When viruses were introduced i.m. at a lower dose $\left(10^{3}\right.$ MICLD $\left._{50}\right)$ the virulence decreased, and no mice inoculated with isolates MOKVSA(252/ 97), LBVCAR1974, LBVSA1982 and LBVSA2006 developed rabies. In contrast, the most significant virulence was observed for isolates LBVSEN1985 and LBVSA2004 (60\% and $40 \%$, respectively).

The duration of incubation periods was also found to be dependent on the specific virus isolate and the route of inoculation, and was proportional to the inoculation dose (Fig. 3). The i.c. inoculation produced the shortest incubation period for all virus isolates tested. RABV (isolate WAmyotis) did not demonstrate a significant difference in the mean incubation periods between $10^{2} \mathrm{MICLD}_{50}$ i.c. and $10^{6} \mathrm{MICLD}_{50}$ i.m., but when introduced i.m. at dose of $10^{3}$ 


$\left.\begin{array}{lll} & \text { ల్లె } & \\ \text { gt1 (AB009663) } & \text { KSVR } & \\ \text { gt4 (AY996322) } & \text { KSVR } \\ \text { gt5 (AY863315) } & \text { KSVR } \\ \text { gt6 (AY863346) } & \text { KSIR } \\ \text { gt7 (NC_003243) } & \text { KSVR } \\ \text { Irkut (AY333112) } & \text { KSIR } \\ \text { Aravan (AY262024) } & \text { KSIR } \\ \text { Khujand (AY262023) } & \text { KSVR } \\ \text { gt3 (S59447) } & \text { KRVD } \\ \text { WCBV (AY333113) } & \text { IKVE } \\ \text { LagSA2003 (EF547421) } & \text { LRVD } \\ \text { LBVSA2006 (EF547422) } & \text { LRVD } \\ \text { Mongoose2004 (EF547423) } & \text { LRVD } \\ \text { LBVSA1982 (EF547425) } & \text { LRVD } \\ \text { LBVZIM1986 (EF547429) } & \text { LRVD } \\ \text { LagSA2004 (EF547428) } & \text { LRVD } \\ \text { LBVCAR1974 (EF547430) } & \text { LRVD } \\ \text { LBVNIG1956 (EF547431) } & \text { LKVD } \\ \text { LBVAFR1999 (EF547432) } & \text { KRVD } \\ \text { LBVSEN1985 (EF547433) } & \text { KRVD }\end{array}\right\}$ Lineage C

Fig. 4. Multiple alignment indicating amino acids 330-333 of the ectodomain of the $\mathrm{G}$ protein of representatives of the lyssavirus genus. GenBank accession numbers of the sequences are indicated.

MICLD $_{50}$, the duration of the incubation period increased to 17 days. For a representative of gt3 [MOKVSA(252/97)], the mean incubation period increased between the i.c. and i.m. inoculations, and only the $10^{6} \mathrm{MICLD}_{50}$ dose caused the disease by the i.m. route, and in one mouse only. The shortest mean incubation periods were observed for LBVSEN1985 and LBVAFR1999 for all the routes of inoculation and over the entire dosage spectrum.

Domains of the lyssavirus $G$ that were previously implicated in pathogenesis were compared between viruses used in our study and other representatives (Figs 4 and 5). Amino-acid positions 330 and 333 on the ectodomain were found to be conserved in genotypes 1, 4, 5, 6, 7, ARAV, IRKV and KHUV but not in gt 2 , gt 3 and WCBV. In gt 2 and gt 3 isolates, $\mathrm{Arg} / \mathrm{Lys}^{333}$ was replaced by an aspartic acid (Asp) (Fig. 4). With the exception of two lineages (B and C) of gt 2 and WCBV, Lys $^{330}$ was found to be conserved within the Lyssavirus genus. The isolates belonging to lineages $\mathrm{B}$ and $\mathrm{C}$ of $\mathrm{gt} 2$, were found to possess Leu $^{330}$. In contrast, isolates belonging to lineage A of gt2 contain $\mathrm{Lys}^{330}$, similar to all other lyssavirus genotypes. A multiple alignment of $\mathrm{G}$ sequences of gt2 representatives used in this study is shown in Figure 5. The lineage A isolates (LBVSEN1985 and LBVAFR1999) demonstrated significant sequence diversity in comparison to the other gt 2 isolates.
Within antigenic site II (positions 34-42 and 198-200), sequence diversity was found at positions 37 and 42 between lineage $C$ isolates and at positions 37, 39, 40, 42, 198 and 200 between the more pathogenic LBV lineage A and the less pathogenic LBV lineage C. Substitutions were also observed in aa 330, 334 and 336 of antigenic site III between lineage A and lineage $\mathrm{C}$ isolates. No differences were observed between LBV isolates for other known antigenic sites within $G$. When anlaysing other sites on the $G$ previously implicated as being significant for pathogenicity (positions 164, 182, 205, 210, 242, 255, 268, 303 ) only position 205 indicated an amino-acid difference between lineage $\mathrm{A}$ and lineage $\mathrm{C}$ isolates (Fig. 5).

\section{DISCUSSION}

The aspect of relative pathogenicity, with reference to inoculum dose and route of inoculation, is an important criterion in considerations of lyssavirus ecology. Previous studies suggested that phylogroup II lyssaviruses were not pathogenic when introduced peripherally. These assertions contributed directly to the suggestion that such viruses are generally less pathogenic, and imply that they have limited public health and veterinary significance [5]. In the present study we have assessed the susceptibility of mice to various isolates that are classified within the lyssavirus gt2 (LBV) in comparison to one isolate each from gt1 (RABV) and gt 3 (MOKV). A single isolate of MOKV and RABV (known to be virulent) were included for the purpose of comparison. When inoculated i.c., all lyssaviruses in our panel caused acute progressive encephalitis (rabies). However, differences were observed when these viruses were inoculated i.m. at peripheral sites distant to the central nervous system (CNS).

We have shown that several representatives of LBV caused rabies in mice when introduced i.m. In the case of MOKV that was inoculated i.m. at a dose of $10^{6}$ MICLD $_{50}$, only $20 \%$ of mice succumbed, whereas the $\mathrm{RABV}$ isolate and two LBV isolates were fatal to the entire respective groups of mice, following the same dose and route of infection. Of even more significance was the finding that even at a reduced viral dose $\left(10^{3}\right.$ MICLD $_{50}$ ) inoculated via the i.m. route, six LBV isolates from lineages $\mathrm{A}$ and $\mathrm{C}$ demonstrated equal or greater pathogenicity to mice than did RABV.

Several studies of the lyssavirus $G$ protein suggested specific epitopes that may be involved in 

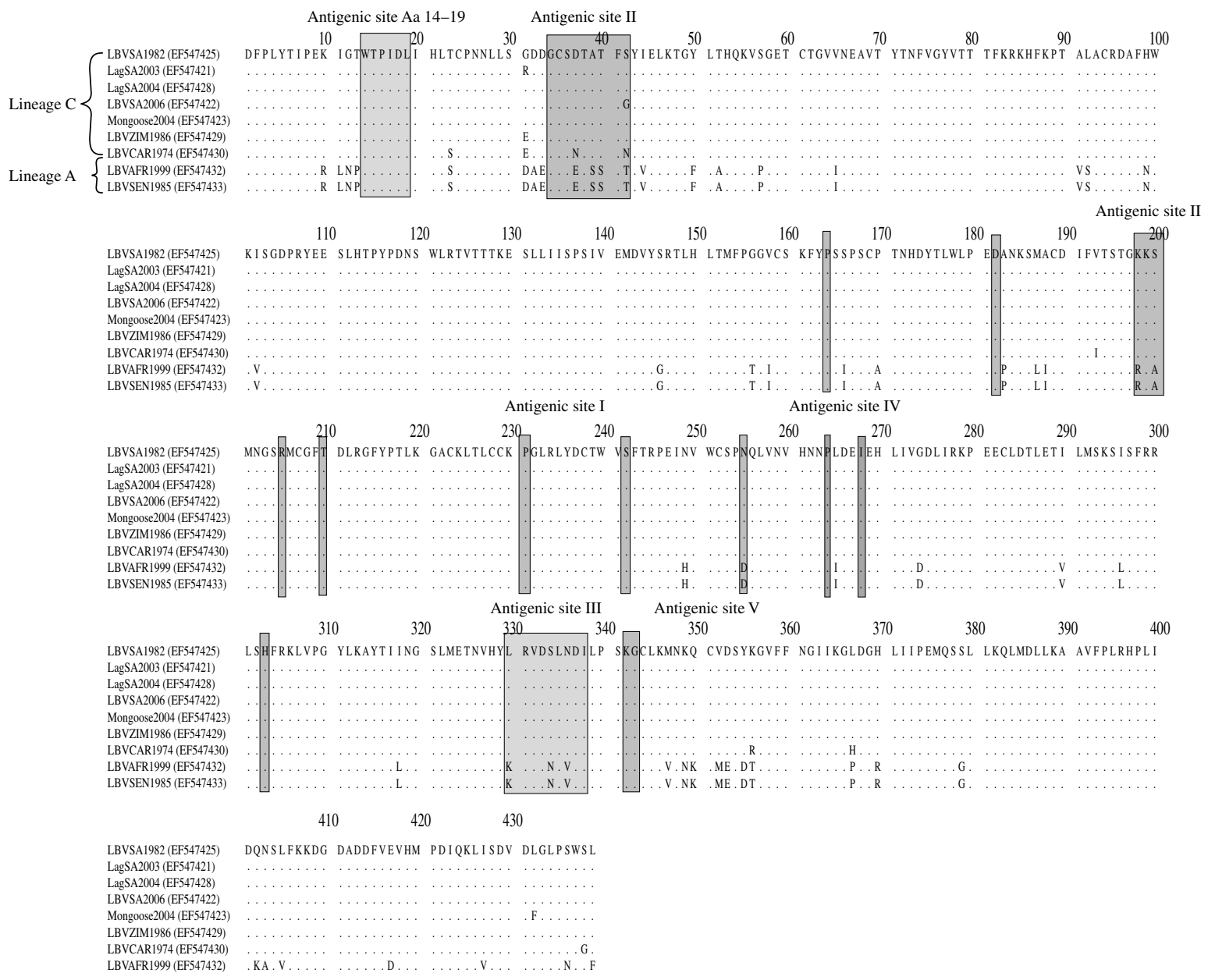

Fig. 5. Multiple alignment indicating differences in the $G$ protein of genotype 2 representatives analysed in pathogenicity studies. Antigenic sites, as well as domains previously indicated as playing a role in pathogenesis are indicated.

pathogenicity. For example, mutations in the G protein can affect pathogenesis as indicated by the aminoacid replacement at position 333 of the ectodomain. The presence of a positively charged amino acid in this position, Arg or Lys, led to a virulent phenotype of RABV while mutations to a Gln, Ile, Gly, Met or Ser led to a less pathogenic or avirulent virus [11, 12, $14,16]$. The aa 333 mutation could also affect the rate of viral spread from cell to cell [23]. A double mutation of aa 330 and aa 333 led to a further reduction of pathogenicity of RABV compared to a single aa 333 substitution $[12,15]$. A recombinant virus with a $\mathrm{Glu}^{333}$ reverted back to a more pathogenic phenotype when $\mathrm{Asn}^{194}$ mutated to Lys ${ }^{194}$ during suckling mouse brain passage [24]. Badrane et al. [5] reported limited peripheral pathogenicity of phylogroup II lyssaviruses, presumably related to the $\mathrm{Asp}^{333}$ in their glycoprotein ectodomain. From the results of our study it is evident that $\mathrm{Asp}^{333}$ is not the sole determinant of reduced pathogenicity since LBV isolates from lineage
$\mathrm{A}\left(\mathrm{Asp}^{333}\right)$ demonstrated the same peripheral pathogenicity to mice as a $\operatorname{RABV}\left(\mathrm{Arg}^{333}\right)$ isolate. The significance of $\mathrm{Lys}^{330}$ within lineage A representatives (similar to the phylogroup I lyssaviruses) distinguishes them from the other LBV lineages, and is difficult to assess. For example, $\mathrm{Lys}^{330}$ is also present in the MOKV isolate that demonstrated reduced peripheral pathogenicity in our study. However, we only analysed one isolate of MOKV, and future studies including different MOKV representatives may provide a better resolution. Mutations in antigenic site II of the $\mathrm{G}$ has previously been shown to render a less pathogenic laboratory RABV strain CVS when introduced i.m. into adult mice [17]. When comparing the amino-acid sequence of antigenic site II of LBV isolates analysed in this study, differences were observed between isolates of lineages A and C. A difference between isolates of lineages $\mathrm{A}$ and $\mathrm{C}$ was also observed in aa 255 , which has previously been implicated as being essential in the pathogenicity of 
the virulent Nishigahara strain (gt1) [16]. Our results suggest that certain LBV representatives, particularly from phylogenetic lineage A (which was recently suggested for consideration as an independent genotype [18]), demonstrate the same or even greater peripheral pathogenicity to mice, as a RABV representative and suggest that the pathogenicity of phylogroup II lyssaviruses has been underestimated. Variation in pathogenicity can occur within a genotype, depending on the strain origin and animal model [25-29]. Even if a mouse is a standard laboratory species for lyssavirus infection, this is not the natural lyssavirus host, and therefore probably not the best model for detailed pathogenesis studies. Indeed, all available phylogroup II isolates were obtained from naturally infected wild and domestic mammals, indicating that these viruses have well established pathways for natural circulation. Intradermal exposures could in some cases be worthy of consideration since LBV is associated with large fruit bats, e.g. Rousettus, Epomophorus and Eidolon [18] from which a bite can easily access mammalian muscles. Our findings clearly indicate the need for improved surveillance and public health precautions for phylogroup II lyssaviruses. Considering that commercially available rabies vaccines do not protect against phylogroup II lyssaviruses, new biologicals which would be capable of protecting against such viruses $[6,8]$, are needed and have been shown to be feasible, at least experimentally [30].

\section{ACKNOWLEDGEMENTS}

The authors thank Dr C. T. Sabeta (Agricultural Research Council, Onderstepoort Veterinary Institute, Rabies Unit, South Africa) for providing the MOKVSA(252/97) and LBVSA1982 isolate and Dr F. Cliquet [Agence Française de Sécurité Sanitaire des Aliments (AFSSA), France] for providing the LBV1999AFR isolate. This study was supported in part by the National Research Foundation of South Africa, the University of Pretoria International Affairs Officee's Postgraduate Study Abroad Bursary Programme, and the US National Vaccine Program Office. Use of trade names and commercial sources are for identification only and do not imply endorsement by the U.S. Department of Health and Human Services. The findings and conclusions in this report are those of the authors and do not necessarily represent the views of the funding agencies.

\section{DECLARATION OF INTEREST}

None.

\section{REFERENCES}

1. Tordo N, et al. Rhabdoviridae. In: Fauquet CM, Mayo MA, Maniloff J, Desselberger U, Ball LA, eds. Virus Taxonomy: The Classification and Nomenclature of Viruses. Eighth Report of the International Committee on Taxonomy of Viruses. London: Elsevier/Academic Press, 2005, pp. 623-644.

2. Botvinkin AD, et al. Novel lyssavirus isolated from bats Russia. Emerging Infectious Diseases 2003; 9: 16231625.

3. Arai YT, et al. New Lyssavirus genotype from the lesser mouse-eared bat (Myotis blythi), Kyrghyzstan. Emerging Infectious Diseases 2003; 9: 333-337.

4. Kuzmin IV, et al. Bat lyssaviruses (Aravan and Khujand) from Central Asia: phylogenetic relationships according to N, P and G gene sequence. Virus Research 2003; 97: 65-79.

5. Badrane H, et al. Evidence of two lyssavirus phylogroups with distinct pathogenicity and immunogenicity. Journal of Virology 2001; 75: 3268-3276.

6. Hanlon CA, et al. Efficacy of rabies biologics against new lyssaviruses from Eurasia. Virus Research 2005; 111: 44-54.

7. Kuzmin IV, et al. Phylogenetic relationships of Irkut and West Caucasian bat viruses within the lyssavirus genus and suggested quantitative criteria based on the $\mathrm{N}$ gene sequence for lyssavirus genotype definition. Virus Research 2005; 111: 28-43.

8. Nel LH. Vaccines for lyssaviruses other than rabies. Expert Review of Vaccines 2005; 4: 533-540.

9. Tignor GH, Shope RE. Vaccination and challenge of mice with viruses of the rabies serogroup. Journal of Infectious Diseases 1972; 125: 322-324.

10. Dietzschold B, et al. Antigenic variation in rabies and rabies-related viruses: cross-protection independent of glycoprotein-mediated virus-neutralizing antibody. Journal of Infectious Diseases 1987; 56: 815-822.

11. Dietzschold B, et al. Characterization of an antigenic determinant of the glycoprotein that correlates with pathogenicity of rabies virus. Proceedings of the National Academy of Sciences USA 1983; 80: 70-74.

12. Seif I, et al. Rabies virus virulence: effect on pathogenicity and sequence characterization of mutations affecting antigenic site III of the glycoprotein. Journal of Virology 1985; 53: 926-935.

13. Coulon $\mathbf{P}$, et al. Invasion of the peripheral nervous system of adult mice by the CVS strain of rabies virus and its avirulent derivative AvO1. Journal of Virology 1989; 63: $3550-3554$.

14. Tuffereau C, et al. Arginine or lysine in position 333 of ERA and CVS glycoprotein is necessary for rabies virulence in adult mice. Virology 1989; 172: 206-212.

15. Coulon $\mathbf{P}$, et al. An avirulent mutant of rabies virus is unable to infect motoneurons in vivo and in vitro. Journal of Virology 1998; 72: 273-278. 
16. Takayama-Ito M, et al. A highly attenuated rabies virus HEP-Flury strain reverts to virulent by single amino acid substitution to arginine at position 333 in glycoprotein. Virus Research 2006; 119: 208-215.

17. Prehaud $\mathbf{C}$, et al. Antigenic site II of the rabies virus glycoprotein: structure and role in viral virulence. Journal of Virology 1998; 62: 1-7.

18. Markotter W, et al. Phylogeny of Lagos bat virus: challenges for lyssavirus taxonomy. Virus Research 2008; 135: 10-21.

19. Dean DJ, Abelseth MK, Atanasiu P. The fluorescent antibody test. In: Meslin FX, Kaplan MM, Koprowski $\mathrm{H}$, eds. Laboratory Techniques in Rabies. Geneva: World Health Organization, 1996, pp. 88-95.

20. Aubert FA. Methods for the calculation of titres. In: Meslin FX, Kaplan MM, Koprowski H, eds. Laboratory Techniques in Rabies. Geneva: World Health Organization, 1996, pp. 445-459.

21. Koprowski H. The mouse inoculation test. In: Meslin FX, Kaplan MM, Koprowski H, eds. Laboratory Techniques in Rabies. Geneva: World Health Organization, 1996, pp. 80-87.

22. Jeanmougin F, et al. Multiple sequence alignment with Clustal X. Trends in Biochemical Sciences 1998; 23: 403-405.

23. Dietzschold B, et al. Differences in cell-to-cell spread of pathogenic and apathogenic rabies virus in vivo and in vitro. Virology 1985; 56: 12-18.

24. Faber M, et al. A single amino acid change in rabies virus glycoprotein increases virus spread and enhances virus pathogenicity. Journal of Virology 2005; 79: 14141-14148.

25. Constantine DG. Transmission experiments with bat rabies isolates: responses of certain carnivora to rabies virus isolated from animals infected by nonbite route. American Journal of Veterinary Research 1966; 27: 13-15.

26. Constantine DG. Transmission experiments with bat rabies isolates: reaction of certain carnivora, opossum, and bats to intramuscular inoculations of rabies virus isolates from free-tailed bats. American Journal of Veterinary Research 1966; 27: 16-19.

27. Constantine DG. Transmission experiments with bat rabies isolates: bite transmission of rabies to foxes and coyote by free-tailed bats. American Journal of Veterinary Research 1966; 27: 20-23.

28. Constantine DG, Solomon GC, Woodall DF. Transmission experiments with bat rabies isolates: Responses of certain carnivores and rodents to rabies viruses from four species of bats. American Journal of Veterinary Research 1968; 29: 181-190.

29. Baer GM, Bales GL. Experimental rabies infection in the Mexican freetail bat. Journal of Infectious Diseases 1967; 117: 82-90.

30. Bahloul C, et al. DNA-based immunisation for exploring the enlargement of immunological cross-reactivity against the lyssaviruses. Vaccine 1998; 16: 417-425.

31. Von Teichman BF, et al. Mokola virus infection: description of recent South African cases and a review of the virus epidemiology. Journal of South African Veterinary Association 1998; 69: 169-171.

32. Sureau $\mathbf{P}$, et al. Isolation of the Lagos bat virus in the Central African Republic [in French]. Bulletin de la Société de Pathologie Exotique 1977; 70: 467-470.

33. Swanepoel R. Rabies. In: Coetzer JAW, Tustin RC, eds. Infectious Diseases of Livestock: with Special Reference to Southern Africa, 2nd edn. Cape Town, South Africa: Oxford University Press, 2004, pp. 1123-1182.

34. Institute Pasteur. Isolations of Lagos bat virus in West Africa. Internal reports of Centre Collaborateur OMS de Reference et Recherche Pour les Arbovirus. Dakar, Senegal, 1985 (http://www.pasteur.fr/recherche/ banques/).

35. Foggin CM. Rabies and rabies-related viruses in Zimbabwe: historical, virological and ecological aspects. Ph.D. thesis, University of Zimbabwe, Harare, 1988.

36. Picard-Meyer E, et al. Epidemiology of rabid bats in France, 1989 to 2002. Veterinary Record 2004; 4: 774-777.

37. Markotter W, et al. Recent Lagos bat virus isolations from bats (suborder Megachiroptera) in South Africa. Emering Infectious Diseases 2006; 12: 504-506.

38. Markotter W, et al. Isolation of Lagos bat virus from water mongoose. Emerging Infectious Diseases 2006; 12: 1913-1918

39. Markotter W, et al. Epidemiology and pathogenicity of African bat lyssaviruses. Developmental Biology (Basel) 2008; 131: 317-325. 